\title{
Extracardiac Stimulation
}

National Cancer Institute

\section{Source}

National Cancer Institute. Extracardiac Stimulation. NCI Thesaurus. Code C99951.

This manifests as stimulation by the lead of non-cardiac structures such as the diaphragm, chest wall, or pectoral muscle. (ACC) 